\title{
Experimental dispersal of recovering Diadema antillarum increases grazing intensity and reduces macroalgal abundance on a coral reef
}

\author{
Silvia Maciá ${ }^{1, *}$, Michael P. Robinson ${ }^{2}$, Abigail Nalevanko ${ }^{1}$ \\ ${ }^{1}$ Barry University, School of Natural and Health Sciences, 11300 NE 2nd Ave., Miami Shores, Florida 33161, USA \\ ${ }^{2}$ Department of Biology, University of Miami, PO Box 249118, Coral Gables, Florida 33124, USA
}

\begin{abstract}
The 1983 mass mortality of the sea urchin Diadema antillarum greatly decreased grazing intensity on Caribbean reefs, contributing to widespread increases in algal abundance and exacerbating decreases in coral cover. Urchin populations have been recovering in some areas, most notably the reefs of Jamaica's north coast. We manipulated the density of $D$. antillarum in the buttress zone of a previously unstudied Jamaican reef where the recovering urchins have a clumped distribution. Some buttresses have a large number of urchins while others nearby have none. We transplanted half of the urchins from high urchin density donor buttresses to low urchin density recipient buttresses. Transplantation significantly decreased the percent cover of macroalgae and increased the amount of bare space. These changes occurred despite a generally low retention of transferred urchins on recipient buttresses. Those urchins remaining on the recipient buttresses aggregated at rugose locations around which algae-free barrens appeared. Transplantation of urchins decreased their local density while maintaining overall density on the reef. The increase in algal consumption after transplantation implies that aggregated urchins compete for algae. Whereas aggregated $D$. antillarum tend to graze within the same area and have only a localized effect on algae, dispersed urchins compete less and eat more. Increased bare space could enhance recruitment of corals, further improving reef health. Our methods could potentially be used as an inexpensive reef restoration tool. Such restoration projects would be most effective if recipient sites with natural or artificially increased rugosity are used.
\end{abstract}

KEY WORDS: Diadema antillarum · Coral reef · Grazing · Competition · Macroalgae · Reef restoration $\cdot$ Rugosity $\cdot$ Buttress zone

Resale or republication not permitted without written consent of the publisher

\section{INTRODUCTION}

In the past few decades, many coral reefs throughout the Caribbean have experienced a phase shift from coral-dominated to algal-dominated ecosystems (Gardner et al. 2003). Various factors have contributed to this phase shift, including overfishing (Hay 1984, Pandolfi et al. 2003, Hawkins \& Roberts 2004), anthropogenic nutrient inputs (Lapointe 1997), widespread coral disease (Gladfelter 1982, Harvell et al. 1999, Aronson \& Precht 2006), and hurricanes (Hughes et al. 1987). The 1983-84 Caribbean-wide mass mortality of the sea urchin Diadema antillarum (Lessios et al. 1984), a major grazer of macroalgae on coral reefs, contributed directly to the increase in macroalgae and also exacerbated the declines in coral cover caused by the other disturbances (Bak et al. 1984, Carpenter 1988 Lessios 1988, Levitan 1988, Aronson \& Precht 2006). In Jamaica, where the mortality rates of $D$. antillarum were $93-100 \%$, macroalgal cover increased by as much as an order of magnitude over pre-die-off levels (Hughes et al. 1985). Coral cover on some Jamaican reefs, which had already undergone a significant decline following Hurricane Allen in 1980, was further reduced to almost zero by algal overgrowth (Hughes et al. 1987). 
Populations of Diadema antillarum on several reefs on the north coast of Jamaica have recently begun to recover (Aronson \& Precht 2000, Carpenter \& Edmunds 2006). On Lee Reef, St. Ann's Bay (see Maciá \& Robinson 2005 for map), we observed highly patchy recovery of urchins. Before the die-off, the density of D. antillarum was 5.9 urchins $\mathrm{m}^{-2}$ at a site $2 \mathrm{~km}$ west of Lee Reef (Hughes et al. 1985). In 2003, we observed a maximum mean urchin density of $1.4 \mathrm{~m}^{-2}$ on Lee Reef, approximately $24 \%$ of pre-die-off levels of the nearby reef (Hughes et al. 1985). D. antillarum occur primarily in the buttress zone, where steep-walled spurs of reef are separated from each other by channels of sand. Some buttresses on Lee Reef have relatively high populations of urchins (1.4 urchins $\mathrm{m}^{-2}$ ), while others have few, if any (0.02 urchins $\left.\mathrm{m}^{-2}\right)$ and noticeably more algae than buttresses with urchins.

In addition to the obvious buttress-scale aggregation, the urchins were also clumped at a scale of approximately $1 \mathrm{~m}^{2}$ (unpubl. data). We hypothesized that this clumping increased localized competition for algae, causing the urchins to eat less algae than they would if evenly distributed. Such competition could potentially slow the recovery of reefs by decreasing the amount of bare substrate available for coral growth or recruitment. We tested our hypothesis by maintaining the average urchin density on the reef as a whole while distributing the urchins over a larger area (thereby decreasing small-scale population density). This was accomplished by removing half of the urchins from high urchin density buttresses and placing them on similarly sized buttresses with low urchin densities.

We predicted that if the urchins were competing, the decrease in population density on the buttresses would reduce overall competition on the reef. Although the amount of algae on the donor buttresses was expected to increase, we predicted that the corresponding decrease in algae on the recipient buttresses would be greater. Therefore, dispersal of the urchins would lead to a decrease in the total amount of algae on the reef, indicating competition among clumped urchins. Urchin transplantation may also prove to be a simple and inexpensive way to decrease algal abundance and improve the status of stressed Caribbean reefs.

\section{MATERIALS AND METHODS}

Baseline data. Our study was conducted on the forereef buttress zone of Lee Reef, in St. Ann's Bay, Jamaica. We collected baseline data on 24 buttresses between 21 May and 2 June 2003. Twelve initially had high urchin densities (hereafter referred to as 'highurchin buttresses') and 12 had low urchin densities (hereafter referred to as 'low-urchin buttresses'). Each buttress was located between 4.5 and $8 \mathrm{~m}$ depth. We measured the length of each buttress and the width at 3 points along that length: at the shallow end, deep end, and halfway between these 2 points. For the 8 buttresses longer than $20 \mathrm{~m}$, the sampling area was limited to $20 \mathrm{~m}$ from the shallower end. There were no obvious differences between the sampled and unsampled portions on these 8 long buttresses. We calculated buttress area by multiplying the length by the average of the 3 width measurements. In addition, we counted all Diadema antillarum on each buttress.

On each buttress we randomly placed six $1 \mathrm{~m}^{2}$ quadrats and quantified bottom cover with the pointintercept method by identifying the bottom type located directly below each of 16 intercept points. We measured rugosity 5 times at each buttress by randomly placing a $4 \mathrm{~m}$ chain (link size of $35 \mathrm{~mm}$ ) along the reef and measuring the actual linear distance covered. The rugosity index was calculated as the ratio of the chain length $(4 \mathrm{~m})$ to the actual linear distance covered (Miller \& Gerstner 2002); thus, higher values indicate greater rugosity. A value of 1 indicates a completely flat surface. The 5 values per buttress were averaged, and this mean was used in further analyses.

Urchin transplantation and resampling. After the initial surveys, we grouped the buttresses into sets of 4 . Every set had 1 of each of the following treatments: high-urchin control, low-urchin control, donor (initially a high-urchin buttress), and recipient (initially a lowurchin buttress). We allocated buttresses to a set by first pairing high-urchin buttresses based on similar urchin density and area. We then added 2 low-urchin buttresses with areas similar to the first 2 buttresses. Experimental (donor/recipient) and control treatments were assigned randomly to 1 buttress within each high-urchin and each low-urchin pair.

Between 4 and 8 June 2003, we randomly selected half of the urchins from each donor buttress and transplanted them to its recipient, where we placed the urchins approximately $1 \mathrm{~m}$ from each other. Urchins were transported in cages $(65 \times 55 \times 30 \mathrm{~cm})$ made of stiff plastic netting with a mesh size of $3.2 \mathrm{~cm}$ and were either swum or taken by boat to the recipient buttress. The collection, transfer, and distribution of urchins on the recipient buttress took approximately 30 to $45 \mathrm{~min}$ for each donor-recipient pair. Urchins that had to be transported by boat were out of the water for less than 2 min. To control for handling effects, we randomly selected half of the urchins on each high-urchin control buttress and treated them in the same manner as the transplanted urchins except that they were returned to their original buttress. At each buttress we used longjawed calipers to measure the test diameter (TD) of 25 urchins randomly selected from the individuals that were transplanted. We also measured TD of 25 random 
urchins from the individuals not removed from the donor buttresses.

We resampled the buttresses 6 wk (12 to 17 July 2003) and 28 wk (14 to 20 December 2003) after transplantation. We used the same methods described above to count urchins and to measure bottom cover. On some recipient buttresses, urchins removed algae from large areas (barrens), and we made additional rugosity measurements at these barrens. We measured rugosity between 1 and 3 times $(2.0 \pm 0.36$, mean $\pm \mathrm{SE})$ within each barren depending on its size and made the same number of measurements immediately outside each barren. We then calculated an average index for rugosity within and outside of each barren for further comparison.

Between 19 and 25 July 2003, we compared the spatial distribution of Diadema antillarum during the day and at night on all buttresses with at least 14 urchins (total of 17 buttresses). Starting with a haphazardly selected individual urchin, we measured the distance between it and its nearest neighbor. We then measured the distance between the second individual and its next nearest neighbor. This process was repeated until ca. 20 distance measurements were collected for each buttress or until all urchins were sampled if fewer than 20 were present. Daytime sampling was conducted between 07:00 and 09:00 h. Nighttime sampling was conducted between 20:30 and 22:30 h, at least 90 min after sunset (18:47 h) and $1 \mathrm{~h}$ after complete darkness fell.

Statistical analyses. Because of the multivariate nature of the benthic assemblages, we initially analyzed them with the PRIMER statistical package (Clarke \& Gorley 2001). We summed the intercept points from all 6 quadrats (16 points for each quadrat) across each buttress for a total of 96 points for each buttress replicate (i.e. 6 replicates per treatment). We constructed a Bray-Curtis similarity index for square root-transformed counts of intercept points. We determined how dissimilar the assemblages of the treatments were by using a 2-way analysis of similarity (ANOSIM) followed by a 1-way ANOSIM. Although a 2-way ANOSIM tests for effects within single factors while holding variation in the other factor constant, it does not allow testing for interactions as does traditional analysis of variance (ANOVA). Therefore, we used a 1-way ANOSIM to perform a post hoc analysis on the week-buttress combinations and test for changes in treatment types over time. The significance of these tests was determined with randomization tests with up to 5000 permutations. We used the SIMPER procedure of PRIMER to determine the benthic types that explained most of the variation among all samples. SIMPER is a step-wise procedure that finds a model to explain the variation in the complete data set. We followed these multivariate analyses with a 2-way randomization ANOVA on the average bare cover and on the average total algal cover. We used a randomization procedure analogous to Tukey's post hoc analyses to search for differences in means.

In addition to a comparison of the 4 treatment types, we tested the 'overall success' of the Diadema antillarum transplantation by examining changes in the benthic assemblages within the 4 buttress sets. We combined the 2 experimental buttresses (donor and recipient) and the 2 control buttresses (low and high urchin density) within each set by adding all of their intercept points. These data were then subjected to PRIMER analyses as before. We also performed a 2-way randomization ANOVA on the average bare cover and on the average total algal cover for the experimental-control combinations.

\section{RESULTS}

Mean $( \pm \mathrm{SE})$ area of the 24 buttresses was $162.4 \pm$ $12.8 \mathrm{~m}^{2}$. The 12 high-urchin buttresses averaged $1.40 \pm$ 0.18 urchins $\mathrm{m}^{-2}$, whereas the 12 low-urchin buttresses averaged $0.02 \pm 0.01$ urchins $\mathrm{m}^{-2}$. High-urchin buttresses had a significantly greater mean rugosity index $(1.41 \pm 0.02)$ than low-urchin buttresses $(1.23 \pm 0.05 ; t=$ 6.67, df $=22, \mathrm{p}<0.0001$ ).

Prior to the urchin transplantation, $68.1 \%$ of the bottom was occupied by algae, $21.5 \%$ by bare rock, $9.6 \%$ by corals, and $<1 \%$ by other organisms. Although we observed a total of 21 species of macroalgae, the benthic community was dominated by 2 macroalgae: Dictyota dichotoma and Halimeda spp. (over $98 \%$ of Halimeda biomass was $H$. opuntia; unpubl. data). D. dichotoma was present in $80 \%$ of all quadrats and covered $36.1 \%$ of the bottom. The calcareous alga $H$. opuntia was present in $84 \%$ of all quadrats and covered $13.6 \%$ of the bottom. Porites was the most common genus of coral, at $7.1 \%$ bottom cover.

We used non-metric multidimensional scaling (NMDS) to represent graphically the variation among the samples caused by the different substratum types (Fig. 1). Overall, the 2 factors of treatment type (2-way ANOSIM: global $\mathrm{R}=0.510, \mathrm{p}<0.01$ ) and week (2-way ANOSIM: global $\mathrm{R}=0.437, \mathrm{p}<0.01$ ) were significant. To compare all combinations of weeks and treatments, we ran a 1-way ANOSIM with each week-treatment combination as a sample. This 1-way analysis was significant overall (global $\mathrm{R}=0.607, \mathrm{p}<0.01$ ). Although the low-urchin control and recipient buttresses appeared distinct during the initial surveys in Week 0 (Fig. 1), pairwise tests revealed no significant difference between them $(R=-0.146, p>0.5)$. Donor buttresses, however, differed significantly from high- 

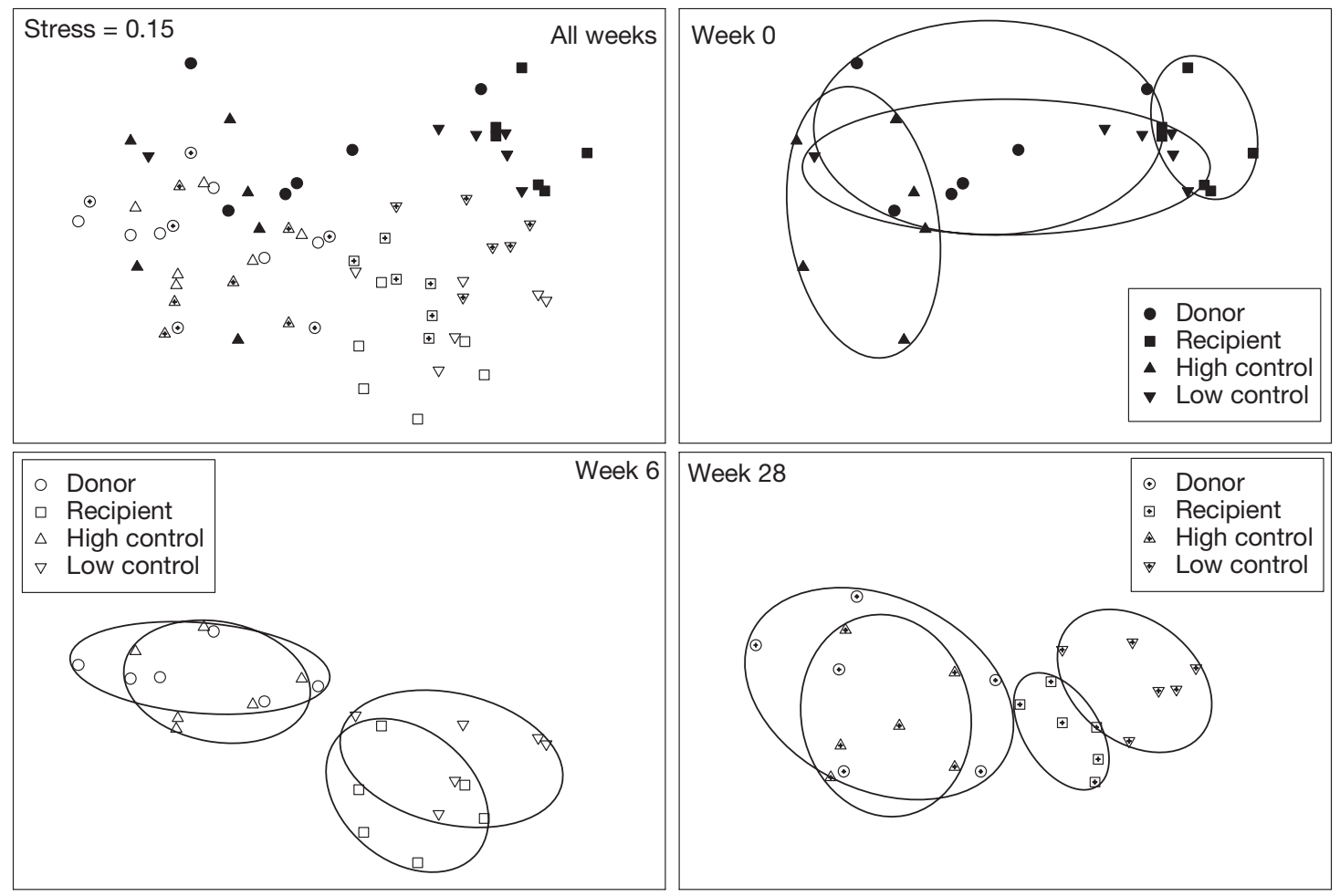

Fig. 1. Two-dimensional NMDS ordinations of square-root transformed benthic cover data. Stress value for overall analysis is 0.15. Upper left panel includes all buttresses for every week. Symbols are the same throughout all 4 panels. To more easily compare treatment effects, 3 panels include only those buttresses from the given week. Ellipses enclose all 6 buttresses of a single treatment for the given week. Axes were held constant throughout the 4 panels so that each symbol has the same relative position

urchin control buttresses at Week $0(\mathrm{R}=0.196, \mathrm{p}=$ 0.030). This difference was largely the result of greater abundances of Dictyota dichotoma and Millepora on donor buttresses and of Porites, Agaricia, and bare substratum on high-urchin control buttresses. $D$. dichotoma and bare substratum contributed rather inconsistently to these differences, however, as indicated by their relatively low scores for dissimilarity/SD (Table 1).

Post hoc analyses revealed a significant difference between recipient and low-urchin control buttresses by Week $6(\mathrm{R}=0.257, \mathrm{p}=0.030)$, and this difference increased by Week $28(\mathrm{R}=0.341, \mathrm{p}=0.020)$. The initial difference observed between high-urchin control and donor buttresses had disappeared by Week 6 ( $\mathrm{R}=$ $-0.102, \mathrm{p}>0.5)$ and was not apparent at Week $28(\mathrm{R}=$ $-0.015, \mathrm{p}=0.489$ ).

Relative to the low-urchin controls, recipient buttresses at Week 0 tended to have less bare substratum, less cover by Porites, and more cover by Dictyota dichotoma and Halimeda spp. (Table 2), but there was no significant difference between the 2 treatments. At Week 6 there was a significant difference, attributable primarily to more bare substratum and lower $D$. dichotoma cover on the recipient buttresses (Table 2). Several other species contributed to this dissimilarity, although none nearly as much as bare space and $D$. dichotoma (i.e. all other dissimilarity/SD values $<1.45$ ). Halimeda spp. made a moderate contribution to the difference between these 2 treatments, but it was much less important than at Week 0 . At Week 28, the 2 most important contributors to the significant dissimilarity were again bare substratum and $D$. dichotoma (Table 2). As in Week 6, recipient buttresses had more bare substratum and less $D$. dichotoma than their controls. These 2 substratum types combined for nearly $30 \%$ of the dissimilarity between the 2 treatments. Other benthic types that had discriminating power nearly as high or higher than bare substratum included crustose coralline algae, turf algae, and Halimeda spp.

Time had a significant effect on benthic cover. With one exception, each treatment type differed significantly from one sampling interval to the next (all $\mathrm{p}<$ 0.010). The one exception was no significant difference between donor buttresses at Weeks 6 and $28(\mathrm{R}=$ 0.022, $\mathrm{p}=0.372$ ).

The 2-way randomization ANOVA revealed that algal cover was significantly affected by both the treat- 
ment $\left(F_{3,60}=43.844, \mathrm{p}<0.001\right)$ and the time $\times$ treatment interaction $\left(F_{6,60}=2.302, \mathrm{p}=0.035\right)$ but not time alone $\left(F_{2,60}=2.372, \mathrm{p}=0.102\right)$. Post-hoc comparisons within each week (Fig. 2) demonstrated significantly less macroalgal cover on the recipient buttresses than the low-urchin control buttresses at Week 28 ( $\mathrm{p}=$ 0.041). A similar test on bare substratum cover (Fig. 2) found a significant difference for treatment only $\left(F_{3,60}=\right.$
20.555, $\mathrm{p}<0.001)$, but not time $\left(F_{2,60}=0.092, \mathrm{p}>0.5\right)$ or their interaction $\left(F_{6,60}=1.268, \mathrm{p}=0.277\right)$. At Week 28, recipient buttresses had significantly more bare space than low-urchin control buttresses $(p=0.002)$ and did not differ from the high-urchin control or donor buttresses. At Week 28, there were no significant differences in algal or bare space cover between the highurchin controls and the donor buttresses.

Table 1. Organisms contributing the most to differences between donor and high urchin-control buttresses at Week 0. Important species determined using SIMPER analysis in PRIMER. Mean abundances of each bottom type in the 2 treatments are included. Mean contribution of each benthic type to the dissimilarity between the 2 treatments and this mean value divided by its SD are also reported. The latter represents the consistency with which each benthic type contributes to overall dissimilarity (i.e. how good it is as a discriminator). Percent contribution of each benthic type to the dissimilarity and its cumulative contribution are also included (only those benthic types that contributed to the first $50 \%$ of total dissimilarity). Average dissimilarity between buttress types was 33.20. CCA: crustose coralline algae

\begin{tabular}{|lrccccc|}
\hline $\begin{array}{l}\text { Benthic } \\
\text { type }\end{array}$ & $\begin{array}{c}\text { Mean abundance } \\
\text { Donors }\end{array}$ & $\begin{array}{c}\text { Mean contribution } \\
\text { to dissimilarity }\end{array}$ & $\begin{array}{c}\text { Dissimilarity/ } \\
\text { SD }\end{array}$ & \% contribution & Cumulative \% \\
\hline $\begin{array}{l}\text { Dictyota } \\
\text { Bare }\end{array}$ & 25.17 & 8.00 & 3.98 & 1.08 & 11.99 & 11.99 \\
Porites & 30.83 & 38.50 & 2.72 & 0.94 & 7.19 & 20.18 \\
Millepora & 7.00 & 14.00 & 2.51 & 1.74 & 7.57 & 27.75 \\
Agaricia & 4.17 & 1.17 & 2.33 & 1.54 & 6.83 & 41.76 \\
CCA & 1.00 & 3.50 & 2.27 & 1.52 & 5.70 & 47.30 \\
Halimeda & 8.17 & 11.50 & 1.89 & 1.24 & 5.87 \\
\hline
\end{tabular}

Table 2. Organisms contributing the most to differences between recipient and low urchin-control buttresses grouped by sampling date. Data presented as in Table 1. Given its importance to the local benthic community, we have included Halimeda whether or not it contributed to the first $50 \%$ of total dissimilarity. CCA: crustose coralline algae

\begin{tabular}{|c|c|c|c|c|c|c|}
\hline $\begin{array}{l}\text { Benthic } \\
\text { type }\end{array}$ & $\begin{array}{r}\text { Mean } \\
\text { Recipient }\end{array}$ & $\begin{array}{l}\text { abundance } \\
\text { Low-urchin controls }\end{array}$ & $\begin{array}{l}\text { Mean contribution } \\
\text { to dissimilarity }\end{array}$ & $\begin{array}{l}\text { Dissimilarity/ } \\
\text { SD }\end{array}$ & $\%$ contribution & Cumulative \% \\
\hline \multicolumn{7}{|c|}{ Week 0 ; avg. dissimilarity $=28.43$} \\
\hline Bare & 2.33 & 10.83 & 3.78 & 0.98 & 13.30 & 13.30 \\
\hline Porites & 0.83 & 5.50 & 3.09 & 1.01 & 10.88 & 24.18 \\
\hline Dictyota & 57.00 & 48.67 & 2.81 & 0.82 & 9.87 & 34.06 \\
\hline Halimeda & 15.50 & 13.17 & 2.26 & 1.28 & 7.95 & 42.01 \\
\hline Turf algae & 1.17 & 1.17 & 1.98 & 1.12 & 6.97 & 48.98 \\
\hline $\mathrm{CCA}$ & 13.00 & 12.33 & 1.85 & 1.35 & 6.52 & 55.49 \\
\hline \multicolumn{7}{|c|}{ Week 6; avg. dissimilarity $=28.54$} \\
\hline Bare & 10.17 & 5.50 & 3.63 & 2.46 & 12.72 & 12.72 \\
\hline Dictyota & 6.00 & 14.83 & 2.80 & 1.79 & 9.83 & 22.55 \\
\hline Galaxaura & 4.33 & 1.83 & 2.29 & 1.31 & 8.03 & 30.58 \\
\hline Porites & 1.67 & 1.83 & 1.86 & 1.32 & 6.50 & 37.08 \\
\hline Amphiroa & 1.67 & 0.17 & 1.75 & 1.30 & 6.13 & 43.21 \\
\hline Lobophora & 2.33 & 0.67 & 1.75 & 1.37 & 6.12 & 49.33 \\
\hline Turf algae & 4.83 & 3.83 & 1.65 & 1.17 & 5.78 & 55.11 \\
\hline Halimeda & 35.17 & 31.17 & 1.39 & 1.36 & 4.87 & 64.94 \\
\hline \multicolumn{7}{|c|}{ Week 28; avg. dissimilarity $=28.52$} \\
\hline Bare & $14.33^{2}$ & 2.50 & 4.36 & 1.43 & 15.27 & 15.27 \\
\hline Dictyota & 12.83 & 32.67 & 4.03 & 2.20 & 14.15 & 29.42 \\
\hline Jania & 8.83 & 5.50 & 2.15 & 1.04 & 7.55 & 36.97 \\
\hline Sargassum & 3.50 & 5.17 & 2.14 & 1.19 & 7.51 & 44.48 \\
\hline $\mathrm{CCA}$ & 22.50 & 15.67 & 1.73 & 1.42 & 6.05 & 50.53 \\
\hline Halimeda & 24.50 & 23.33 & 1.42 & 1.45 & 4.98 & 66.88 \\
\hline
\end{tabular}




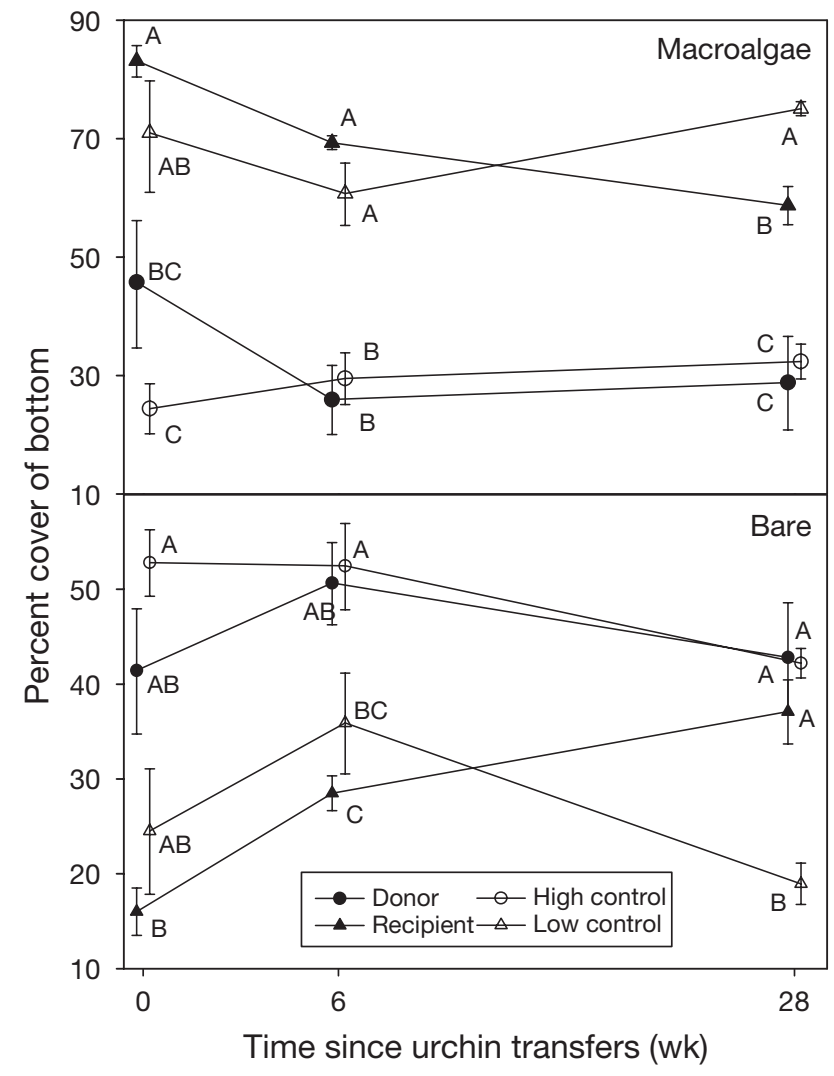

Fig. 2. Percent cover of macroalgae and bare space for 4 different buttress treatments at 3 different sampling intervals. Urchins were transferred from donor to recipient buttresses following Week 0 . Means $( \pm 1 \mathrm{SE}$ ) have been back-transformed from arcsine transformations. Shared letters indicate means within each week that are not statistically different based on post hoc analyses from a randomization ANOVA $(\alpha=0.05)$. High and low control buttresses are controls with high and low densities of urchins, respectively. Note the different scales on the $y$-axes

\section{Overall effect of urchin transplantation: experimental vs. control buttresses}

Although the benthic assemblages of the combined experimental and combined control buttresses had a large overlap initially, the separation between them increased through time and was quite strong by Week 28 (Fig. 3). A 2-way ANOSIM was significant for both treatment (global $\mathrm{R}=0.185, \mathrm{p}=0.006$ ) and time (global R $=0.662, p<0.001$ ). A 1 -way ANOSIM found no differences between the control and experimental buttresses at Week $0(R=0.135, p=0.052)$ or at Week 6 $(\mathrm{R}=0.157, \mathrm{p}=0.117)$, but the 2 groups differed significantly at Week $28(\mathrm{R}=0.261, \mathrm{p}=0.030)$. This difference at Week 28 was largely a result of less Dictyota dichotoma cover and more bare substratum on experimental buttresses (Table 3). These 2 benthic types contributed more than $37 \%$ of the total dissimilarity between the 2 buttress types.

These multivariate analyses were supported by 2-way randomization ANOVA on the percentage of total algal cover and of bare cover. The only significant effect for algal cover was the time $\times$ treatment interaction $\left(F_{2,30}=\right.$ $6.553, \mathrm{p}=0.003$ ). Post hoc analyses indicated that the only within-week difference between experimental and control buttresses was at Week 0 when there was significantly more algal cover on the experimental buttresses $(63.2 \pm 4.3 \%)$ than the controls $(46.4 \pm 5.7 \% ; \mathrm{p}=0.008)$. Bare cover was significantly affected by time $\left(F_{2,30}=\right.$ $4.438, \mathrm{p}=0.018$ ) and the time $\times$ treatment interaction $\left(F_{2,30}=5.665, \mathrm{p}=0.006\right)$. Post hoc analyses indicated that relative to the control buttresses, the experimentals had significantly less bare space $(28.5 \pm 3.4 \%$ vs. $38.4 \pm 3.2 \%$; $\mathrm{p}=0.043)$ at Week 0 but more at Week $28(38.8 \pm 3.8 \%$ vs. $26.7 \pm 1.4 \% ; \mathrm{p}=0.038)$. There was no difference at Week $6(p=0.395)$.

\section{Experimental transplant and urchin behavior}

The mean TD of transplanted urchins $(65.8 \pm 0.7 \mathrm{~mm})$ did not differ significantly (ANOVA with original buttress as blocking factor: $F_{1,301}=3.032, \mathrm{p}=0.082$ ) from the mean TD of urchins that were not removed from the donor buttresses $(67.4 \pm 0.7 \mathrm{~mm})$. Most recipient buttresses had low retention of transplanted urchins. Half of the recipient buttresses retained at least $35 \%$ of the transplanted urchins after $6 \mathrm{wk}$, but only 2 buttresses retained that many urchins after $28 \mathrm{wk}$

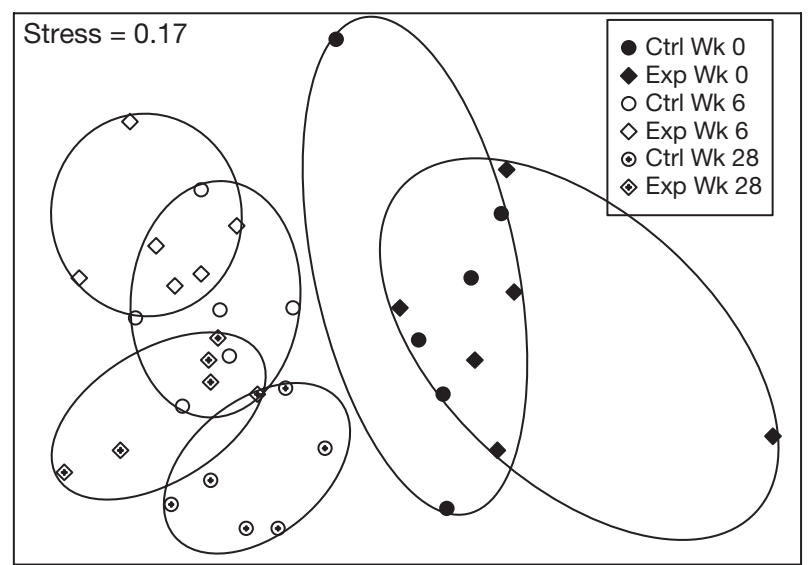

Fig. 3. Two-dimensional NMDS ordinations of square-root transformed benthic cover data representing combined cover data from control buttresses (low- and high-urchin density) and experimental buttresses (donors and recipients) within a buttress set. Each data point represents 2 buttresses (total of 192 point intercepts) during a single week. Stress value for the analysis is 0.17 . Ellipses enclose all 6 groups of a single treatment for a given week 
Table 3. Organisms contributing the most to differences between experimental (donor and recipient combined) and control (low-urchin and high-urchin combined) buttresses at Week 28. Data presented as in Table 1. CCA: crustose coralline algae

\begin{tabular}{|c|c|c|c|c|c|c|}
\hline \multirow{2}{*}{$\begin{array}{l}\text { Benthic } \\
\text { type }\end{array}$} & \multicolumn{2}{|c|}{ Mean abundance } & \multirow{2}{*}{$\begin{array}{c}\text { Mean contr. to } \\
\text { dissimilarity }\end{array}$} & \multirow{2}{*}{$\begin{array}{l}\text { Dissimilarity/ } \\
\text { SD }\end{array}$} & \multirow[t]{2}{*}{$\%$ contribution } & \multirow[t]{2}{*}{ Cumulative \% } \\
\hline & Controls & Experimentals & & & & \\
\hline Dictyota & 37.33 & 17.67 & 5.12 & 1.89 & 20.23 & 20.23 \\
\hline Bare & 26.67 & 38.83 & 4.30 & 1.84 & 16.97 & 37.20 \\
\hline Halimeda & 36.50 & 37.83 & 3.04 & 1.25 & 12.00 & 49.20 \\
\hline Porites & 19.17 & 18.00 & 1.97 & 1.43 & 7.77 & 56.97 \\
\hline CCA & 32.00 & 38.67 & 1.87 & 1.37 & 7.37 & 64.34 \\
\hline Turf algae & 10.50 & 6.33 & 1.48 & 1.19 & 5.83 & 70.17 \\
\hline Millepora & 3.83 & 7.33 & 1.42 & 1.49 & 5.60 & 75.77 \\
\hline Jania & 8.00 & 10.33 & 1.27 & 0.94 & 5.03 & 80.80 \\
\hline Sargassum & 6.17 & 4.00 & 1.06 & 0.92 & 4.17 & 84.97 \\
\hline Agaricia & 2.50 & 4.33 & 0.77 & 1.28 & 3.03 & 88.00 \\
\hline Filamentous & 2.00 & 2.67 & 0.58 & 1.33 & 2.29 & 90.29 \\
\hline
\end{tabular}

(Table 4). Retention of the non-transplanted urchins on the donor buttresses was never lower than $82 \%$ at either 6 or 28 wk and was significantly greater than on recipient buttresses for both periods (2 Wilcoxon matched pair signed ranks tests [WMPSR], both: $T \mathrm{~s}=$ $0, n=6, p=0.031$ ). Retention on donor buttresses did not differ from the high-urchin controls (where urchins were subjected to handling) at Week 6 and Week 28 (minimum $71 \%$ retention for both; 2 Mann-Whitney $U$-tests, both: $\left.U<27, \mathrm{n}_{1}=\mathrm{n}_{2}=6, \mathrm{p}>0.20\right)$.

Within a few days of transplantation, urchins were noticeably clumped on recipient buttresses. These aggregations were always at elevated or highly rugose locations around which the urchins created conspicuous areas with little or no algal cover, in stark contrast to the highly dense algae surrounding them. Six barrens were located on 5 separate recipient buttresses. The 2 barrens on the same buttress were distinctly separate and created by 2 independent aggregations of urchins. The rugosity index was always higher inside these barrens than in the area immediately surrounding them (Fig. 4; WMPSR: $\mathrm{n}=6, T \mathrm{~s}=0$, $\mathrm{p}=0.031)$.

Table 4. Diadema antillarum. Retention of urchins transplanted from donor to recipient buttresses. Number of urchins added was half of the total population of the donor buttress

\begin{tabular}{|lrrrrr|}
\hline $\begin{array}{l}\text { Recipient } \\
\text { buttress }\end{array}$ & $\begin{array}{c}\text { No. urchins } \\
\text { added }\end{array}$ & $\begin{array}{c}\text { After 6 wk } \\
\text { No. urchins } \\
\text { present }\end{array}$ & $\begin{array}{c}\text { After 28 wk } \\
\text { present }\end{array}$ & $\begin{array}{c}\text { No. urchins } \\
\text { present }\end{array}$ & $\begin{array}{c}\text { urchins } \\
\text { present }\end{array}$ \\
\hline 1 & 50 & 43 & 86.0 & 38 & 76.0 \\
2 & 173 & 130 & 75.1 & 72 & 41.6 \\
3 & 93 & 35 & 37.6 & 13 & 14.0 \\
4 & 35 & 6 & 17.1 & 4 & 11.4 \\
5 & 105 & 16 & 15.2 & 9 & 8.6 \\
6 & 42 & 4 & 9.5 & 2 & 4.8 \\
\hline
\end{tabular}

\section{Nocturnal and diurnal distribution of urchins}

To compare the nocturnal and diurnal urchin distributions, we calculated the median distance between urchins for each buttress at night and during the day. The mean of those medians was significantly smaller during the day $(16.4 \pm 2.2 \mathrm{~cm})$ than at night $(23.8 \pm$ $2.9 \mathrm{~cm}$; WMPSR: $T \mathrm{~s}=34, \mathrm{n}=17, \mathrm{p}=0.044)$.

\section{DISCUSSION}

The sea urchin Diadema antillarum was once a common and important grazer on Caribbean reefs (Lessios et al. 2001). Relative to pre-die-off levels, the currently recovering populations of $D$. antillarum are small and scattered (Aronson \& Precht 2000, Miller et al. 2003), and individuals within these populations can occur in a clumped distribution (Carpenter \& Edmunds 2006, Lee 2006, this study).

We transplanted $D$. antillarum from areas where they were relatively common to nearby areas where they were virtually absent. Our transplantation protocol involved both the removal and addition of urchins (from donor and to recipient buttresses, respectively). Multivariate analyses revealed significant differences in benthic cover between the recipient and low-urchin control buttress 6 and 28 wk posttransfer. These differences resulted largely from increases in bare space and decreases in the macroalga Dictyota dichotoma on the recipient buttresses. After $28 \mathrm{wk}$, recipient buttresses had a significantly lower percent cover of macroalgae and significantly more bare space relative to 


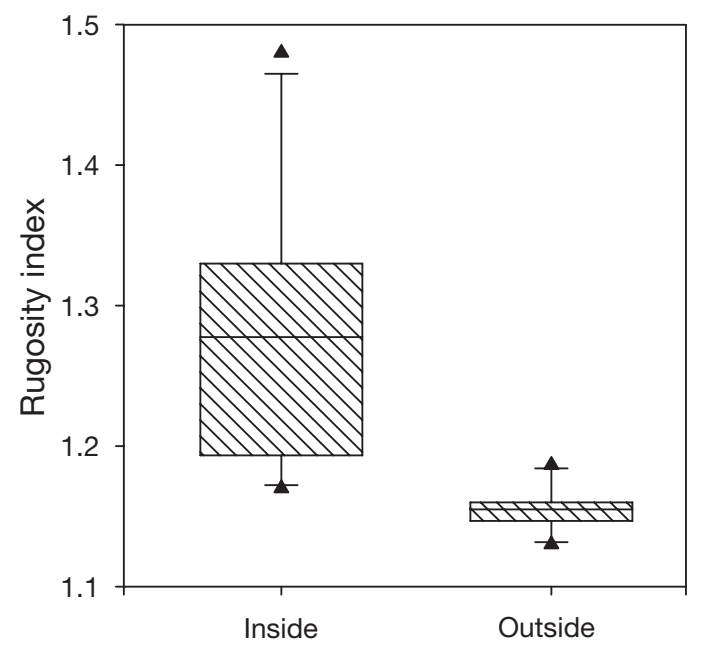

Fig. 4. Box plots of reef rugosity inside and immediately outside algal barrens on recipient buttresses 28 wk after urchin transplantation. Higher rugosity index values indicate more rugose surfaces. Box plots constructed as follows: middle horizontal line: median; boxes encompass the central $50 \%$ of data $(25 \%$ above and $25 \%$ below the median); error bars:

$90 \%$ confidence limits; $\mathbf{\Lambda}$ : data points beyond these limits

their low-urchin control buttresses. In addition, at 28 wk biomass of $D$. dichotoma was significantly lower on recipient buttresses than on low-urchin controls (unpubl. data).

To infer that the transplantation improved the overall health of the reef, however, requires that the total amount of algae on the experimental buttresses (i.e. recipients and donors combined) be less than on the controls. Transplantation of urchins did decrease the amount of algae on the experimental buttress pairs relative to the controls. Prior to the urchin transfer, algal percent cover was higher on the experimental buttresses than on the control buttresses. By the end of the experiment, however, algal cover on experimental buttresses had decreased such that there was no difference from the controls. ANOSIM analyses also indicated that the benthic community was significantly different between the experimental and control buttresses, primarily as a result of lower cover of Dictyota dichotoma (less than half as much, Table 3) and the greater amount of bare space on the experimental buttresses. Finally, at the end of the experiment, the biomass of $D$. dichotoma was significantly lower on experimental buttresses than on controls (unpubl. data).

By dispersing Diadema antillarum, we decreased the local (buttress-scale) densities of the urchins while maintaining their overall (reef-scale) population density. This dispersal led to a decrease in macroalgae and increase in bare space relative to initial conditions. In other words, the per capita grazing rate increased under dispersed conditions, implying that intraspecific competition is occurring in the recovering urchin pop- ulation. Such competition is likely caused by the tendency of these urchins to aggregate. Clumped urchins tend to graze within the same relatively small area, creating the localized barrens we observed around aggregations of urchins. During their nocturnal foraging activities, D. antillarum spread out over a greater area. Such nocturnal dispersal suggests that the area immediately surrounding the urchin aggregations does not contain enough food for all of the urchins, and hence, intraspecific competition is probably occurring.

Our results imply that although the populations of $D$. antillarum are recovering, the recovery of Caribbean coral reefs is progressing more slowly than possible. After being experimentally spread out, urchins forage less in previously grazed areas and encounter and consume larger amounts of algae. Although early studies demonstrated intraspecific competition among $D$. antillarum prior to or shortly after the die-off (Bak \& van Eys 1975, Levitan 1988, 1989), ours is the first study to suggest that even at the relatively low densities of recently recovered populations, such competition continues to be an important factor.

\section{Retention of transplanted urchins}

The effects of transplanting Diadema antillarum would probably have been even greater than we observed had the retention of urchins been higher on the recipient buttresses. Only 2 recipient buttresses retained more than $35 \%$ of their transplanted urchins. It appears that the urchins did not die but rather migrated away from recipient buttresses. Firstly, retention on high-urchin control buttresses, where urchins were subjected to handling controls, was high and did not differ from the donor buttresses. Secondly, we spent a significant amount of time observing these buttresses during the first $8 \mathrm{wk}$ of the experiment, and we never saw any $D$. antillarum that appeared unhealthy or any remains of deceased urchins. Finally, because of overfishing, St. Ann's Bay lacks large fishes and other potential urchin predators (pers. obs.).

Reef rugosity was probably the most important factor in urchin retention. Although previous work has indicated that higher urchin abundances occur in more rugose coral reef areas (van den Hoek et al. 1978, Hunte \& Younglao 1988, Miller et al. 2003, Lee 2006), only one of these studies actually quantified rugosity (Lee 2006). At our study site, high-urchin buttresses had a significantly higher rugosity index than lowurchin buttresses. Furthermore, the areas on donor buttresses where transplanted urchins aggregated had significantly higher rugosity than the immediately surrounding areas. Diadema antillarum are proficient bioeroders of coral reefs (Bak 1994). It is possible that the 
greater rugosity on high-urchin buttresses was at least partially caused by bioerosion from the urchins themselves, but the rapid (within a few days) aggregation of transplanted urchins on rugose areas indicates an active preference for topographically complex substratum.

\section{Implications for recovery of Caribbean reefs}

Our experiment has implications for the recovery of Caribbean coral reefs and associated reef restoration projects. Although some areas have not shown any recovery (Chiappone et al. 2002, Lessios 2005), Diadema antillarum populations in many areas of the Caribbean have rebounded (Aronson \& Precht 2000, Chiappone et al. 2001, Miller et al. 2003, Carpenter \& Edmunds 2006). Many of these recovering populations have patchy distributions similar to our site (Carpenter \& Edmunds 2006) and could be promising candidates for dispersal. By dispersing recovering populations of urchins, overall macroalgal abundance on the reef may be reduced and bare space increased, without a concomitant increase in algae on the donor buttresses. If the urchins can maintain low levels of algal cover for an extended amount of time, coral cover may eventually increase as observed on other Jamaican reefs (Carpenter \& Edmunds 2006) and predicted by simulation models (Mumby et al. 2006).

The reefs of Jamaica are highly overfished, and predation on Diadema antillarum at our study site is lower than on pristine reefs. It is possible that our methods would have limited success at sites where abundant fish predators may prey on recently transplanted urchins, but given the extent of overfishing throughout the Caribbean (Hay 1981, Alvarado et al. 2004, Debrot \& Nagelkerken 2006, Newman et al. 2006) there are many areas where fish predation should not affect transplanted urchins. Furthermore, our methods require sites with a recovering population of $D$. antillarum. At such candidate sites, the very presence of urchins would indicate that predators are not capable of completely removing the urchin population.

Increased rugosity is directly linked to urchininduced decreases in macroalgal cover (Lee 2006). In our study, urchin retention was greater in more rugose areas. Therefore, practical applications of our transplant procedure would be most effective on recipient sites with high rugosity. Rugosity could be artificially increased with the addition of 3-dimensionally complex structures (e.g. cinder blocks or dead coral fragments) that can be secured to the reef. Alternatively, using recipient locations where Diadema antillarum cannot easily leave, such as patch reefs, could also improve retention.
Acknowledgements. Thanks to J. F. Morrissey, T. Leigh, C. Leigh, and S. Smith for logistical and field help, N. Glass for field and lab help, and the Jamaican National Environment and Planning Agency for granting the necessary permits. K.L. Semon assisted with PRIMER analyses, and 3 anonymous reviewers greatly improved the manuscript with their comments. Funding was provided by the Barry University Research Scholarship Fund. This is contribution \#11 of the Hofstra University Marine Lab.

\section{LITERATURE CITED}

Alvarado JJ, Cortés J, Salas E (2004) Population densities of Diadema antillarum Phillipi at Cahuita National Park (1977-2003), Costa Rica. Caribb J Sci 40:257-259

Aronson RB, Precht WF (2000) Herbivory and algal dynamics on the coral reef at Discovery Bay, Jamaica. Limnol Oceanogr 45:251-255

Aronson RB, Precht WF (2006) Conservation, precaution, and Caribbean reefs. Coral Reefs 25:441-450

Bak RPM (1994) Sea urchin bioerosion on coral reefs: place in the carbonate budget and relevant variables. Coral Reefs 13:99-103

Bak RPM, van Eys G (1975) Predation of the sea urchin Diadema antillarum Philippi on living coral. Oecologia 20:111-115

Bak RPM, Carpay MJE, de Ruyter van Steveninck ED (1984) Densities of the sea urchin Diadema antillarum before and after mass mortalities on the coral reefs of Curaçao. Mar Ecol Prog Ser 17:105-108

Carpenter RC (1988) Mass mortality of a Caribbean sea urchin: immediate effects on community metabolism and other herbivores. Proc Natl Acad Sci USA 85:511-514

Carpenter RC, Edmunds PJ (2006) Local and regional scale recovery of Diadema promotes recruitment of scleractinian corals. Ecol Lett 9:271-280

Chiappone M, Miller SL, Swanson DW, Ault JS, Smith SG (2001) Comparatively high densities of the long-spined sea urchin in the Dry Tortugas, Florida. Coral Reefs 20:137-138

Chiappone M, Swanson DW, Miller SL, Smith SG (2002) Large-scale surveys on the Florida Reef Tract indicate poor recovery of the long-spined sea urchin Diadema antillarum. Coral Reefs 21:155-159

Clarke KR, Gorley RN (2001) PRIMER v. 5: User Manual/Tutorial, PRIMER-E, Plymouth

Debrot AO, Nagelkerken I (2006) Recovery of the long-spined sea urchin Diadema antillarum in Curaçao (Netherlands Antilles) linked to lagoonal and wave sheltered rocky habitats. Bull Mar Sci 79:415-424

Gardner TA, Cote IM, Gill JA, Grant A, Watkinson AR (2003) Long-term region-wide declines in Caribbean corals. Science 301:958-960

Gladfelter WB (1982) White-band disease in Acropora palmata: implications for the structure and growth of shallow reefs. Bull Mar Sci 31:639-643

Harvell CD, Kim K, Burkholder JM, Epstein PR and 8 others (1999) Emerging marine diseases-climate links and anthropogenic factors. Science 285:1505-1510

Hawkins JP, Roberts CM (2004) Effects of artisanal fishing on Caribbean coral reefs. Conserv Biol 18:215-226

Hay M (1984) Patterns of fish and urchin grazing on Caribbean coral reefs: are previous results typical? Ecology 65:446-454

Hay ME (1981) Spatial patterns of grazing intensity on a Caribbean barrier reef: herbivory and algal distribution. 
Aquat Bot 11:97-109

Hughes TP, Keller BD, Jackson JBC, Boyle MJ (1985) Mass mortality of the echinoid Diadema antillarum Philippi in Jamaica. Bull Mar Sci 36:377-384

Hughes TP, Reed DC, Boyle M (1987) Herbivory on coral reefs: community structure following mass mortalities of sea urchins. J Exp Mar Biol Ecol 113:39-59

Hunte W, Younglao D (1988) Recruitment and population recovery of Diadema antillarum (Echinodermata; Echinoidea) in Barbados. Mar Ecol Prog Ser 109:109-119

Lapointe BE (1997) Nutrient thresholds for bottom-up control of macroalgal blooms on coral reefs in Jamaica and southeast Florida. Limnol Oceanogr 42:1119-1131

Lee SC (2006) Habitat complexity and consumer-mediated positive feedbacks on a Caribbean coral reef. Oikos 112: 442-447

Lessios HA (1988) Mass mortality of Diadema antillarum in the Caribbean: what have we learned? Annu Rev Ecol Syst 19:371-393

Lessios HA (2005) Diadema antillarum populations in Panama after twenty years following mass mortality. Bull Mar Sci 24:125-127

Lessios HA, Robertson DR, Cubit JD (1984) Spread of Diadema mass mortality through the Caribbean. Science 226:335-337

Lessios HA, Garrido MJ, Kessing BD (2001) Demographic history of Diadema antillarum, a keystone herbivore on Caribbean reefs. Proc R Soc Lond B 268:2347-2353

Levitan DR (1988) Algal-urchin biomass responses following mass mortality of Diadema antillarum Philippi at Saint

Editorial responsibility: Charles Birkeland (Contributing

Editor), Honolulu, Hawaii, USA
John, U. S. Virgin Islands. J Exp Mar Biol Ecol 119: 167-178

Levitan DR (1989) Density-dependent size regulation in Diadema antillarum: effects on fecundity and survivorship. Ecology 70:1414-1424

Maciá S, Robinson MP (2005) Effects of habitat heterogeneity in seagrass beds on grazing patterns of parrotfishes. Mar Ecol Prog Ser 303:113-121

Miller MW, Gerstner CL (2002) Reefs on an uninhabited Caribbean island: fishes, benthic habitat, and opportunities to discern reef fishery impact. Biol Conserv 106:37-44

Miller RJ, Adams AJ, Ogden NB, Ogden JC, Ebersole JP (2003) Diadema antillarum 17 years after mass mortality: is recovery beginning on St. Croix? Coral Reefs 22:181-187

Mumby PJ, Hedley JD, Zychaluk K, Harborne AR, Blackwell PG (2006) Revisiting the catastrophic die-off of the urchin Diadema antillarum on Caribbean coral reefs: fresh insights on resilience from a simulation model. Ecol Model 196:131-148

Newman MJH, Paredes GA, Sala E, Jackson JBC (2006) Structure of Caribbean coral reef communities across a large gradient of fish biomass. Ecol Lett 9:1216-1227

Pandolfi JM, Bradbury RH, Sala E, Hughes TP and 8 others (2003) Global trajectories of the long-term declines of coral reef ecosystems. Science 301:955-958

van den Hoek C, Breeman AM, Bak RPM, van Buurt G (1978) The distribution of algae, corals and gorgonians in relation to depth, light attenuation, water movement and grazing pressure in the fringing coral reef of Curaçao, Netherlands Antilles. Aquat Bot 5:1-46

Submitted: July 7, 2006; Accepted: February 23, 2007

Proofs received from author(s): August 2, 2007 